\title{
NOMES PRÓPRIOS GERAIS NO CONTEXTO DA SEMÂNTICA DE J. S. MILL
}

\author{
Lúcio Lourenço PRADO 1
}

- RESUMO: O presente artigo apresenta argumentos em defesa da hipótese de que nomes próprios gerais são impossíveis no contexto da filosofia geral de Stuart Mill. Minha tese é contrária à posição de John Skorupski sobre esta questão. Ofereço dois argumentos que representam, respectivamente, duas diferentes perspectivas: pragmático e sistemático. No primeiro, analiso o problema dos nomes próprios gerais no contexto da linguagem natural. No segundo, discuto o problema no contexto interno do Sistema de Lógica de Mill.

- PALAVRAS-CHAVE: nome; significado; conotação; denotação; semântica.

\section{Introdução}

Em seu livro John Stuart Mill, ${ }^{2}$ John Skorupiski afirma, indicando uma suposta falha na tese milliana de que todos os nomes gerais são conotativos, que os nomes gerais não podem receber o tratamento dado por Mill por não se tratar de uma única classe de nomes. Haveria, segundo Skorupiski, nas linguagens naturais, três classes de nomes gerais, sendo que dessas somente uma seria composta por nomes conotativos. Sua argumentação tem como base a afirmação de que a semântica de Mill não dá conta de casos que supostamente ocorrem na linguagem natural; esses casos seriam: a) quando se atribui um nome

1 Professor de Filosofia na Faculdade de Filosofia e Ciências da Unesp de Marília.

2 SKORUPSKI, J.: John Stuart Mill, col. The arguments of philosophers, Routledge, Londres e N. York, 1999 
próprio a mais de um indivíduo num mesmo sentido; b) quando um nome geral não faz referência a determinada(s) propriedade(s) que os objetos denotados devem possuir para que este lhes possa ser verdadeiramente predicado, mas quando, em vez disso, elege-se uma amostra (sample) de indivíduos pertencentes uma determinada classe de objetos e atribui-se o nome geral a todos os objetos que são conformes a ela. Na presente exposição, será posta em dúvida a primeira alternativa proposta por Skorupski de nomes gerais não-conotativos, ou seja, será questionada aqui a possibilidade de se atribuir, em linguagens realisticamente concebidas, nomes próprios a mais de um indivíduo no mesmo sentido. Vale lembrar que a segunda classe de nomes gerais não conotativos proposta por Skorupski também é passível de ser discutida e colocada sob suspeita; entretanto, na presente exposição, somente a primeira tese será considerada.

A discussão aqui proposta tem como pano de fundo, como já foi mencionado, a semântica de Mill. Por isso, será necessário, antes de adentrarmos no nosso problema propriamente dito, realizar uma breve exposição acerca de algumas passagens importantes do Sistema de lógica, ${ }^{3}$ a fim de recuperamos alguns conceitos que serão pressupostos tanto na colocação de nosso problema quanto em nossa argumentação.

\section{I}

O Sistema de lógica busca, como o próprio nome sugere, estabelecer de forma sistemática e global os fundamentos da lógica. Na realidade, Mill escreve seu sistema de lógica para, a partir dele, fundamentar sua filosofia política, suas teorias econômicas, etc. Sua lógica teria por objetivo, assim, fornecer os elementos instrumentais mais elementares para a derivação de sua filosofia como um todo. Nosso interesse, no entanto, restringe-se ao aspecto eminentemente lógico-semântico de seu pensamento.

Para Mill, o objeto da lógica ${ }^{4}$ consiste na determinação de como, e com a ajuda de que critérios, se pode, no que se refere ao conhecimento

3 MILL, J. S.: System of logic. in: The Collected works of John Stuart Mill. London and Toronto: Routledge and University of Toronto Press, 1973.

4 Claro deve estar que, para Mill, a lógica tem uma parte dedutiva e uma indutiva; a primeira, que é aquela da qual estamos falando aqui, diz respeito às verdades derivadas obtidas por meio de raciocínios; a segunda, que consta da segunda metade do Sistema de lógica, diz respeito à maneira pela qual obtemos proposições universais a partir da experiência sensível, uma vez que esta só fornece proposições singulares. 
não-intuitivo, em coisas não evidentes por si mesmas, distinguir o que está provado do que não está. ${ }^{5}$ Conhecimento intuitivo, ainda segundo Mill, é aquele que pode ser obtido de forma imediata, pelo testemunho direto dos sentidos; conhecimento não-intuitivo é aquele derivado, obtido por inferência a partir de verdades já estabelecidas. ${ }^{6}$ A Lógica é, pois, arte do pensar, do raciocínio e da argumentação - e o que Mill entende por raciocínio e argumentação é o estabelecido pela silogística clássica.

Independentemente do fato de a análise que Mill realiza acerca dos fundamentos da lógica ser correta ou não (o que não nos interessa aqui particularmente), o principal ponto a ser salientado no que diz respeito às questões estritamente semânticas que permeiam esta exposição é o fato de o Sistema de lógica começar por uma análise da linguagem e, mais especificamente, dos nomes. Deve-se, antes de se fazer quaisquer considerações sobre o "funcionamento" da lógica propriamente dito, sobre as regras de inferência que determinam a derivação de verdades não-intuitivas a partir de verdades estabelecidas, realizar um inventário completo de todos os tipos de nomes e, mais especificamente, de como e o que esses nomes significam. A análise e classificação dos nomes terão como resultado uma teoria do significado (meaning) bastante própria: em última análise, o significado é determinado pela conotação e não pela denotação dos nomes. Mais adiante, esta tese será retomada de forma um pouco mais detalhada e dentro de seu contexto sistemático.

O fato de Mill ter iniciado seu Sistema de lógica com uma análise da linguagem é assim justificado:

A Lógica é uma parte da arte do pensar; a linguagem, de acordo com o testemunho de todos os filósofos, é, evidentemente, um dos principais instrumentos úteis ao pensamento (...) Um espírito que, sem estar previamente instruído sobre a justificação e o justo emprego das diversas classes de palavras, empreendesse o estudo dos métodos de filosofar, seria como aquele que quisesse chegar a ser observador em astronomia sem ter aprendido a acomodar a distância focal dos instrumentos de ótica para uma visão distinta. ${ }^{7}$

Está claro nesta passagem que Mill comunga com a concepção já presente no Sofista de Platão de que o pensamento é uma atividade eminentemente simbólica, que necessita da "mediação" da linguagem para se realizar. Por isso, se a lógica se pretende ciência e arte do racio-

5 MILL, J. S.: op. cit. 1, I, p.1.

6 Idem: Introdução, 1.

7 Idem. 
cínio $^{8}$ - este entendido eminentemente como manifestação do pensamento - um tratado de Lógica deve ser iniciado por uma análise da linguagem. Há, no entanto, uma razão mais forte e filosoficamente mais relevante, embora não completamente dissociada da anterior, para Mill ter iniciado seu Sistema de lógica pela análise da linguagem e, mais especificamente, dos nomes (tese esta que será retomada pelo futuro logicismo de Frege, Russell e Cia.): que o significado das palavras (ou, no caso, dos nomes) que compõem uma proposição determina o significado da própria proposição; e a proposição, esta sim, é o objeto primeiro da lógica, pois tudo o que pode ser verdadeiro ou falso deve assumir a forma proposicional:

Tudo o que pode ser objeto de crença ou não crença deve expressar-se por palavras, e tomar a forma de uma proposição. (...) É preciso indispensavelmente conhecer o significado (import) das palavras para conhecer o significado das proposições. $^{9}$

Para Mill, numa proposição, um nome (predicado) é sempre afirmado ou negado de outro nome (sujeito); os termos sujeito e predicado são conectados pela cópula ('é', 'não é', ou qualquer outra inflexão do verbo ser), que tem também a função de determinar se o predicado é afirmado ou negado do sujeito. ${ }^{10}$ Torna-se evidente, assim, que para determinar os tipos de proposições com os quais o pensamento trabalha é necessário conhecer os tipos de nomes que se compõem em proposições.

É esse, em linhas gerais, o entorno que orienta o inventário dos nomes realizado por Mill e que, por sua vez, é o terreno onde se dará a discussão acerca da plausibilidade ou não da tese de que todos os nomes gerais são conotativos. Passemos, então, ainda em linhas gerais, à classificação dos nomes realizada no Sistema de lógica.

\section{II}

A classificação dos nomes é efetuada no Sistema de lógica através de distinções sucessivas; ao final das distinções, forma-se uma comple-

8 Esta posição de Mill com respeito à natureza da lógica, que a considera ao mesmo tempo como ciência e arte, obtida em parte a partir da obra do arcebispo de Whately, é motivo de polêmica entre os historiadores; a partir dela é possível construir um poderoso argumento em favor de um já embrionário antipsicologismo lógico em Mill. O próprio Skorupski, com quem estamos dialogando aqui, trabalha nesse sentido. Este problema, porém, nos levaria a mares muito profundos e nos desviaria de nosso problema específico.

9 Mill. J.S. Op. cit., 1, I, p.1.

10 idem: 1, I, 2 
xa teia de nomes e estruturas semânticas, cujo principal conceito é o de conotação. Por motivo de economia e para não multiplicar desnecessariamente o uso de termos técnicos, somente as distinções diretamente relevantes para o estabelecimento da tese da conotabilidade dos nomes gerais serão mencionadas.

A primeira distinção que nos interessa divide os nomes em singulares e gerais. Um nome singular é aquele que somente pode ser predicado verdadeiramente e com o mesmo sentido de um único objeto. ${ }^{11}$ Por oposição, um nome geral pode ser predicado verdadeiramente e com o mesmo sentido de um número indeterminado de objetos. Nomes próprios, tais como João, Maria, São Paulo, Pelé são claramente nomes singulares. Já os nomes que tomam a forma de adjetivos, que aparecem na maioria das vezes como predicado de proposições, tais como branco, velho, sábio, são exemplos de nomes gerais; há, certamente, uma infinidade de objetos dos quais se pode predicar verdadeiramente e no mesmo sentido cada um desses três nomes, e isto porque cada um desses nomes determina um critério que os objetos em geral devem obedecer para poderem ser deles predicados; tal critério consiste em que os objetos possuam um determinado atributo (exatamente o mesmo atributo), no caso, a brancura, a velhice e a sabedoria.

Os nomes singulares, por sua vez, não se resumem aos nomes próprios, aos "nomes de batismo", àqueles que são impressos muitas vezes arbitrariamente aos indivíduos, simplesmente com o objetivo de distingui-lo dos demais, como os nomes citados mais acima (João, Maria, etc.); esta caneta, ou o atual presidente da República são nomes que somente podem ser predicados verdadeiramente e num mesmo sentido de um único objeto; são, portanto, singulares, mas não próprios, pois podem oferecer um critério para sua predicação e este critério pode consistir na posse ou não de algum atributo, como acontece com os nomes gerais.

Não se pode, entretanto, tomar por nome geral um nome coletivo. $O$ XV Regimento de Infantaria do Exército Britânico é um nome singular, embora o próprio regimento seja composto por um grande número de indivíduos; trata-se, no entanto, de um único regimento e é ao regimento que o nome se refere. Nomes gerais referem-se a uma pluralidade de

11 Mill utiliza o termo indivíduo em vez de objeto. Utilizo, no entanto, o termo objeto porque efetuo uma distinção entrre os nomes que é alheia a Mill, a saber, a distinção entre nomes coletivos (considerados por Mill) e individuais (não considerados por Mill). Como utilizarei o termo "indivíduo" nesse sentido, utilizarei o termo "objeto" como sendo aquilo denotado pelos nomes singulares. 
objetos e nunca a um objeto, mesmo que este seja, em sua natureza, coletivo e, assim, composto por uma série de indivíduos. O soldado João não é o XV Regimento, mas um membro desse regimento.

Com base nesta definição de nomes coletivos, que será bastante útil em nossa argumentação posterior, sugiro uma nova distinção, que Mill não realiza explicitamente, mas que, a meu ver, é perfeitamente coerente com seu sistema: irei distinguir nomes individuais dos nomes coletivos. Claro deve estar que aquilo que chamo de nome individual não deve ser confundido com o que foi chamado de nome singular. Nome singular se opõe a nome gera,l e estas categorias são determinadas pelo tipo de nomeação exercido em cada caso e com a "quantidade" de objetos denotados em cada caso. Nome individual se opõe a nome coletivo, distinção esta que não se refere ao tipo de nomeação que protagonizam, mas ao tipo de objeto nomeado; nomes individuais e nomes

coletivos são ambos nomes singulares, pois se referem a um único objeto; entretanto, se o objeto denotado é um indivíduo, trata-se de um nome individual; se é uma unidade complexa, composta por mais de um indivíduo, trata-se de um nome coletivo.

\section{III}

A segunda distinção entre os nomes que será mencionada é também a mais importante que Mill realiza. Trata-se da distinção entre nomes conotativos e não-conotativos. Um nome não-conotativo é aquele que se refere a um sujeito ou a um atributo somente; um termo conotativo designa um sujeito e implica um ou mais atributos. Devemos, aqui, entender por sujeito tudo aquilo que possua atributos. ${ }^{12}$ Exemplos de nomes não-conotativos são: João, São Paulo, Brasil; exemplos de nomes conotativos são: virtuoso, branco, grande.

A diferença fundamental existente entre essas duas classes de nomes reside no fato de que uma delas, a primeira, compreende nomes que são atribuídos aos indivíduos arbitrariamente, com o único objetivo de distingui-lo dos demais, sem, no entanto, apresentar nenhuma informação acerca desse indivíduo; são os chamados nomes próprios. A outra classe compreende nomes que se referem aos indivíduos dos quais podem ser verdadeiramente predicados não por mera associação arbitrária, mas porque determinam um ou mais atributos que os indivíduos

12 MILL, J.S. Op. cit., II, p.5. 
em geral devem possuir para que possam ser por eles nomeados. Um indivíduo é chamado João por uma livre escolha de seus pais que assim resolveram chamá-lo para distingui-lo das demais pessoas. Em princípio, porém, poderia receber qualquer outro nome sem prejuízo de sua própria natureza, pois o nome João não nos informa nada acerca desta natureza. É bem verdade - e Mill deixa isso bem claro - que pode ter havido algum motivo positivo para que lhe pusessem esse nome:

Um homem pode se chamar João porque esse era o nome de seu pai; uma vila pode se chamar Dartmouth porque está situada na embocadura do rio Dart; Não há, porém, nada na significação da palavra João que implique que o pai do indivíduo assim chamado também possua esse nome; nem, tampouco, na palavra Dartmouth que esta vila esteja situada na desembocadura do rio Dart. Se a areia viesse a obstruir a desembocadura do rio (...), nem por isso nome da vila mudaria necessariamente. ${ }^{13}$

Isso não acontece com os nomes conotativos. Um indivíduo é chamado virtuoso não porque este nome lhe tenha sido atribuído arbitrariamente, mas porque o nome "virtuoso" implica, compreende, indica ou, como Mill prefere dizer, conota um determinado atributo que todo indivíduo deve possuir para que o nome virtuoso possa dele ser predicado verdadeiramente, a saber, a virtude. Pode-se afirmar, em última instância, que os nomes conotativos são "criteriais" (segundo Skorupski: criterial names) na medida em que fornecem um critério bem determinado que deve ser obedecido pelos indivíduos que por eles são nomeados. Possuem, pois, uma carga semântica que vai muito além da mera associação de palavras a idéias, defendida pelo nominalismo clássico. ${ }^{14}$ Nomes conotativos referem-se a indivíduos, mas o fazem através da afirmação de algo que positivamente esses indivíduos possuem. O que existe em comum entre todos os indivíduos denotados pelo nome "homem" não é somente o nome "homem", mas a posse de uma série de atributos conotados por esse nome. Toda vez que se pronuncia a palavra homem, além de se referir diretamente aos indivíduos dos quais essa palavra é nome, se refere também, indiretamente, a todos os atributos relacionados à humanidade: vida animal, racionalidade, mortalidade,

13 Idem

14 Skorupski afirma em seu livro que Mill não deixa de ser um nominalista de acordo com O sentido moderno do termo; é, no entanto, um crítico do nominalismo tal como expresso classicamente por pensadores como Hobbes, por exemplo. Ver SKORUPSKI, J.: op. cit., pp. 59 e seguintes. 
etc. E sabemos que somente a posse de todos esses atributos em conjunto garante a predicação verdadeira desse nome a qualquer indivíduo.

A teoria da conotação traz consigo uma conseqüência bastante significativa no que diz respeito À teoria semântica de Mill: que somente os nomes conotativos propriamente têm significação ou, o que vem a ser o mesmo, que a significação dos nomes é determinada por aquilo que eles conotam e não pelo que eles denotam. $\mathrm{O}$ argumento para a sustentação desta tese baseia-se no fato de que nomes de diferentes conotações podem ter a mesma denotação e, no entanto, não podem ter o mesmo significado. Significação, para Mill, é uma relação que envolve positivamente uma atribuição e, portanto, deve subministrar alguma informação acerca dos indivíduos denotados. Não é supérfluo apontar aqui que esta maneira de se encarar o processo de significação coloca as bases a partir das quais as discussões posteriores sobre lógica e linguagem vão se dar, sobretudo a partir de Frege e sua distinção entre sentido e referência. ${ }^{15}$

Uma última observação acerca dos nomes conotativos: nada impede que um nome singular, aquele que somente pode ser predicado verdadeiramente e num mesmo sentido de um único indivíduo, seja conotativo. De fato, a maioria dos nomes singulares é constituída por nomes próprios; porém, há uma série de nomes que conotam algum atributo mas, dada uma determinada circunstância, esse atributo somente possa ser possuído por um único indivíduo: o pai de Sócrates é um exemplo significativo.

\section{IV}

Na forma de um parêntese, uma importante observação se faz necessária neste momento. Pelo que foi exposto até aqui, pode parecer que há uma certa ambigüidade na maneira como Mill estabelece sua teoria dos nomes. O autor parece confundir ou, na melhor das hipóteses, não clarificar dois aspectos importantes que envolvem o uso dos nomes: o uso referencial (quando o nome aparece na posição de sujeito na proposição) e o uso predicativo (quando ocorre na posição de predicado). Tal ambigüidade, porém, é apenas aparente dentro do contexto sistemático de Mill. Isso porque, de acordo com a estrutura da teoria milliana dos nomes e de seu conceito de proposição, o que estabelece esta su-

15 FREGE, G.: Sinn und bedeutung. 
posta distinção não são elementos de ordem semântica, mas sim de ordem sintática e, portanto, alheios às questões que estão sendo abordadas aqui. Mill trabalha com uma estrutura proposicional aos moldes aristotélicos, ${ }^{16}$ ou seja, para ele uma proposição deve ser composta por um termo sujeito e um termo predicado, além da cópula que é responsável pela conexão entre ambos. Diferentemente do que ocorre com Frege, onde a estrutura proposicional reduz-se à forma conceito/objeto, que são elementos categorialmente distintos, em Mill não há nenhuma diferença categorial ou estrutural entre os termos sujeito e predicado, mas o que determina esta situação é a posição que cada um assume na proposição. Independentemente do que venham a significar "A" e "B", desde que sejam nomes no sentido amplo que Mill lhes delega, não há nenhum empecilho sintático que proíba a ocorrência tanto da proposição "A é B" quanto da proposição "B é A", sendo somente necessário, em alguns casos, de acordo com os tipos de nomes que ocorrem na proposição, o uso do quantificador. Mas o que deve ficar claro é que, para Mill, ser predicado de uma proposição, ou seja, ser afirmado ou negado de algo, não significa ser uma propriedade atribuída a algo, ou que algo cai sob determinado conceito. Por exemplo: na proposição "Edson Arantes do Nascimento é Pelé", não se afirma que o sujeito representado pelo nome "Edson Arantes do Nascimento" possui a propriedade ou o atributo de ser Pelé - até porque "Pelé" é um nome próprio e, como tal, não conota atributos - mas que o objeto denotado pelo nome "Edson Arantes do Nascimento" é também denotado pelo nome "Pelé". ${ }^{17}$ Por mais paradoxal que possa parecer, para Mill, predicar não é atribuir propriedades, mas afirmar que uma ou várias coisas são referidas por determinado nome. É nesse sentido que podemos afirmar aqui que o nome "João" pode ser predicado verdadeiramente de João. A grande novidade que Mill oferece com relação ao nominalismo clássico não se encontra na maneira como concebe aquilo que a proposição propriamente afirma ou nega (nomes de nomes), mas no modo como concebe o processo de significação dos nomes conotativos, a maneira como esses nomes se referem aos

16 Esta maneira aristotélica de encarar a estrutura proposicional conjugada a uma semântica bastante peculiar, mas herdeira direta do velho nominalismo inglês, produzirá, é bom que se diga, conseqüências nem sempre propriamente aristotélicas.

17 Creio não ser mera coincidência este problema reaparecer no Sinn und Bedeutung de Frege. Parte de minhas pesquisas atuais estão direcionadas a identificar nos chamados artigos semânticos de Frege a influência direta de sua leitura de Mill. Espero, no momento oportuno, poder tornar públicos meus resultados. 
objetos nomeados: pela posse de atributos reais conotados pelo nome. Assim, a proposição "Sócrates é homem" não afirma diretamente que o sujeito (ou a coisa, ou a substância) Sócrates possui a propriedade de ser homem; ao invés disso, afirma que a coisa nomeada pelo nome "Sócrates" é nomeada também pelo nome "homem". Somente de forma indireta algumas propriedades reais são atribuídas a Sócrates. Na medida em que o nome "homem" conota alguns atributos (por exemplo, o de ser bípede, animal, racional, etc.) esses, e somente esses são atribuídos a Sócrates, mas em virtude exclusivamente do que o nome conota e não do que a proposição propriamente afirma de maneira direta. Em última análise, tal proposição afirma o seguinte: o objeto denotado pelo nome "Sócrates" possui todos os atributos conotados pelo nome "homem". Somente desta maneira indireta uma proposição efetivamente pode atribuir ou negar propriedades a objetos.

Torna-se claro diante desses esclarecimentos que os nomes envolvidos no exemplo acima, "Sócrates" e "homem", podem ter suas respectivas posições invertidas numa proposição com sentido, significando exatamente o mesmo. Porém, por ser "homem" um nome geral e, portanto, referir-se, digamos assim, a uma "classe" de indivíduos, será necessária a quantificação. Embora com sentido, é falso afirmar que todo homem é Sócrates; mas é verdadeira, por exemplo, a proposição "algum homem é Sócrates"; pois, alguém que é nomeado pelo nome "homem" é também nomeado pelo nome "Sócrates". Em última instância, tal proposição diz: alguém que possui todos os atributos conotados pelo nome "homem" é referido pelo nome próprio "Sócrates".

Por esses motivos, uma vez que estamos transitando no contexto da semântica de J. S. Mill, trabalhar a partir da distinção entre os uso referencial e predicativo dos nomes, que se estabelecem no âmbito da proposição, é não só desnecessário, mas até contraproducente. Mill não compartilha integralmente daquele que veio a ser chamado de princípio do contexto, no qual oS significados dos termos devem ser estabelecidos a partir do contexto proposicional. Por isso, o papel exercido pelo nome no contexto da proposição - e, conseqüentemente, seu uso referencial ou predicativo - não está diretamente relacionado com sua significatividade, com suas "propriedades semânticas". Por isso, a semântica milliana que estamos apresentando e supondo deve ser considerada, por assim dizer, como possuindo um estatuto pré-proposicional. E a estrutura proposicional, no sistema de Mill, supõe a teoria dos nomes, terreno no qual estamos trabalhando. Trata-se, pois, de um problema que se encontra num nível logicamente posterior ao nosso contexto 
específico e, por isso, acredito, de importância apenas secundária na argumentação que se seguirá.

\section{V}

Diante do que foi exposto até aqui, é possível compreender o alcance da tese milliana à qual nos referimos no início dessa exposição, a saber, de que todos os nomes gerais são conotativos. ${ }^{18}$ Esta tese se segue quase que naturalmente das distinções realizadas acerca dos nomes: um nome geral é aquele que pode ser predicado de um número indeterminado de objetos; um nome conotativo é aquele que fornece critérios que devem ser obedecidos pelos objetos em geral para que possam por ele ser nomeados. Ora, somente deve ser possível para um nome denotar um número indeterminado de objetos se ele oferecer um critério a ser obedecido pelos objetos por ele nomeados. Nomes próprios, ou seja, não-conotativos, são nomes que buscam a singularização das coisas: uma pessoa chama-se João para ser distinguida de José, uma cidade chama-se Marília para ser distinguida de Assis, Bauru, etc.; por isso, esses nomes são arbitrariamente atribuídos às coisas singulares, justamente para salientar essa singularidade .

Não é isso, entretanto, o que pensa Skorupski. Em seu livro já citado, ele levanta (e defende) a possibilidade de nomes serem fixados arbitrariamente (portanto, sem conotação) a mais de um objeto. ${ }^{19}$ Escolhese uma palavra, enumeram-se em seguida alguns objetos que serão nomeados por ela e determina-se, assim, a denotação de um nome; este nome não é singular, pois se aplica a mais de um objeto no mesmo sentido, e não é conotativo, pois não foi oferecido um critério para ser obedecido pelos objetos denotados, mas a denotação foi fixada por enumeração. Poderíamos, assim, ainda segundo Skorupski, chamar esses nomes de nomes próprios gerais ${ }^{20}$ (general proprer names). O termo "próprio", aqui, segue uma analogia com os nomes singulares não conotativos que são chamados nomes próprios.

18 Não nos interessa agora avançar às conseqüências desta tese, mas cabe salientar que ela possui uma importância fundamental para o estabelecimento daquilo que Mill chama de proposições meramente verbais - que são análogas ao que Kant chamou de juízos analíticos, embora recebam, por parte de Mill, um tratamento epistemológico bem diferente.

19 SKORUPSKI, J.: op. cit, p. 57.

20 Deve ficar claro, e Skorupski considera esta questão, que, para Mill, um nome geral se refere a um número indeterminado de indivíduos, e não, simplesmente, a mais de um indivíduo, como no caso mencionado. Este autor chega a sugerir, inclusive, que se considerem tais nomes numa classe à parte, como nomes que não são nem singulares nem gerais. 
Skorupski defende também, além dos nomes próprios gerais, e dos nomes gerais conotativos, a existência de uma terceira classe de nomes gerais, que não são nem próprios (ou seja, não recebem uma fixação arbitrária de conotação) nem conotativos (pois não oferecem critérios para sua predicação). O exemplo dado pelo autor é o nome tigre. Este nome pode ser predicado verdadeiramente de um número indeterminado de objetos. No entanto, tal nome foi atribuído, ainda conforme Skorupski, de forma arbitrária, não a cada um dos objetos por enumeração, como no caso dos nomes próprios gerais, mas por "identificação exaustiva". Ou seja, não é o caso de enumerar arbitrariamente um número de objetos e escolher um nome para denotá-los; deve-se, pois, identificar de forma exaustiva uma série de objetos pertencentes à mesma classe (eu não vejo outra maneira de ler esta identificação exaustiva) e nomear a classe arbitrariamente. Obtém-se uma amostra (sample) de objetos pertencentes a uma classe e, a partir de então, atribui-se o nome a todos os indivíduos que concordam com tal amostra.

No entender de Skorupski, temos, então, três classes de nomes gerais:

a) nomes próprios gerais, aqueles obtidos por enumeração arbitrária;

b) nomes gerais criteriais, aqueles que são, de fato, conotativos, pois oferecem critérios para que os indivíduos possam ser nomeados por eles;

c) nomes gerais nem próprios nem criteriais, como tigre, que não são enumerativos nem conotativos, mas, digamos assim, "exaustivos".

\section{VI}

Na minha compreensão, a tríplice divisão dos nomes gerais proposta por Skorupski não é correta. Entretanto, somente a existência da primeira classe de nomes mencionada acima, a dos nomes próprios gerais, será contestada aqui. A terceira classe de nomes, a dos nomes gerais que não são nem próprios nem criteriais também pode ser, a meu ver, questionada; para isso, trabalhos realizados por autores como Kripke e Searle, por exemplo, podem lançar alguma luz sobre a questão. Entretanto, por ora, tal problema será deixado de lado.

A tese de Skorupski a ser considerada é aquela que afirma a existência de nomes próprios gerais, ou seja, nomes atribuídos arbitraria- 
mente a mais de um objeto, sem oferecer nenhum critério para a determinação de sua denotação. Escolhe-se, por enumeração, um certo grupo de objetos e atribui-se um nome próprio que valha, indistintamente e num mesmo sentido, para cada um desses objetos previamente eleitos. Por exemplo: nada me impediria, em princípio, de escolher o nome "catapufe" arbitrariamente e atribuí-lo a três pessoas de minha relação. Nesse sentido, sempre que fosse pronunciada a palavra "catapufe" o ouvinte seria levado a pensar, não na idéia ${ }^{21}$ de um único objeto, mas nas idéias de três objetos previamente determinados. Portanto, seria legítimo afirmar que o nome "catapufe" denota mais de um objeto exatamente no mesmo sentido. $\mathrm{O}$ autor propõe a existência desta classe de nomes alegando "não ser impossível" que se proceda desta maneira ao atribuir-se um nome. "Não ser impossível", aqui, assume claramente o sentido de "não ser contraditório"; parece ser, em princípio, perfeitamente concebível uma tal situação, até porque, não se deve perder de vista, a arbitrariedade do ato de nomeação é uma característica essencial do nome próprio: se o nome próprio é atribuído arbitrariamente nada impede que, arbitrariamente, um nome seja atribuído a mais de um indivíduo no mesmo sentido. De fato, por este ponto de vista, nenhuma contradição parece existir na atribuição de um nome próprio não a um único objeto, mas a um grupo de objetos. No entanto, parece, somente o recurso à não-contradição não é um critério suficiente para que se possa afirmar a existência de nomes dessa natureza; deve haver motivos mais plausíveis para a aceitação da tese ousada de que nomes gerais possam ser próprios. Proponho duas perspectivas de abordagem deste problema a fim de que se possa, com segurança, analisar as conseqüências da tese de Skorupski: uma pragmática e outra sistemática. A primeira perspectiva parte da seguinte pergunta: Embora não seja impossível, existe, de fato, nas linguagens realisticamente constituídas, o uso de nomes próprios gerais, tal como Skorupski os concebe? A segunda perspectiva pergunta: Há elementos conceituais dentro do sistema de Mill que permitam a consideração desses nomes e forneçam razões para considera-los? Dito de forma mais precisa, a abordagem pragmática buscará analisar a questão dos nomes próprios gerais de forma independente, isto é, sem referência às teses mesmas de Stuart Mill. A abor-

21 No caso particular dos nomes próprios, Mill concorda com o nominalismo de Hobbes que afirma a relação dos nomes a idéias de coisas e não às coisas mesmas. No caso dos nomes conotativos, porém, sua opinião é outra. 
dagem sistemática, ao contrário, irá verificar se, mesmo no caso de não existirem nomes próprios gerais nas linguagens realisticamente concebidas, a tese de Skorupiski possui o valor de ser uma conseqüência ou, na pior das hipóteses, de ser coerente com o Sistema de lógica de Mill.

\section{VII}

Comecemos com a primeira abordagem: existem, de fato, casos em que, aparentemente, um nome próprio é aplicado a mais de um indivíduo no mesmo sentido. Defendo, porém, que nesses casos há, na realidade, dois processos semânticos distintos: temos, primeiramente, a atribuição de um nome próprio coletivo ${ }^{22}$ e, num segundo momento, um nome geral conotativo que denota os membros de uma coletividade. Por exemplo: é certo que podemos predicar o nome beatle verdadeiramente e num mesmo sentido a John, Paul, Ringo e George. Creio também que não há dúvidas de que o nome The Beatles é um nome próprio, atribuído arbitrariamente a um conjunto musical a fim de distingui-lo dos demais. Desta forma, poderíamos crer que o nome beatle, no sentido em que é atribuído a John, Paul, etc., por ser uma variante individual do nome próprio coletivo The Beatles, seja também um nome próprio - e portanto não conotativo - que denota quatro indivíduos exatamente no mesmo sentido. Seria um caso típico de nome geral próprio, tal como Skorupski os define. Entendo que, quando se consideram as coisas desta maneira, comete-se uma confusão.

Vimos, no início desta exposição, que os nomes gerais não podem ser confundidos com os nomes coletivos; nomes gerais denotam um número indeterminado de objetos; nomes coletivos denotam uma única unidade complexa, composta por mais de um indivíduo. Sugiro que, quando se atribui um nome próprio coletivo, que é o caso do The Beatles, fazer parte da coletividade denotada por esse nome torna-se uma propriedade daqueles indivíduos. Ou seja, The Beatles é um nome próprio, não conotativo, arbitrário e coletivo; beatle, tal como pode ser predicado verdadeiramente e num mesmo sentido de John, Paul, Ringo e George é, ao contrário, um nome geral, e como todo bom nome geral, conotativo, pois conota a propriedade de pertencer à coletividade denotada por The Beatles. A relação semântica existente entre o nome The

22 Recordemos a distinção entre nomes coletivos e nomes individuais proposta no início deste trabalho. 
Beatles e o conjunto musical ao qual o nome e refere é de uma natureza completamente diferente daquela existente entre o nome beatle e os membros de tal conjunto. No primeiro caso, o nome não possui propriamente significação e se refere à idéia do conjunto musical, de modo que, toda vez que for pronunciado, o ouvinte saberá do que se está falando; no segundo, o nome significa, ou seja, conota uma propriedade e, assim, determina um critério que deve ser obedecido pelos indivíduos em geral para que possam ser denotados por ele.

Diante disso, defendo que, dentro da abordagem pragmática que sugeri há pouco, embora possa não ser contraditório a ocorrência de casos em que se atribui nomes próprios arbitrariamente a mais de um indivíduo, isso não ocorre de fato. Quando, supostamente, se atribui um nome próprio a mais de um indivíduo no mesmo sentido, se está, em realidade, atribuindo-se um nome coletivo. Até porque, parece não haver outra finalidade no ato de nomeação que atribui o mesmo nome a mais de um indivíduo senão a de agrupar esses indivíduos numa unidade complexa, mesmo que tal agrupamento não seja, em princípio, determinado pela posse de alguma propriedade aparente. Porém, uma vez atribuído esse nome, os indivíduos denotados por ele passam a possuir ao menos uma propriedade em comum, a saber, a de serem membros da mesma coletividade denotada pelo nome coletivo.

Tenho consciência, entretanto, que minha tese, para ser coerente, deve supor uma certa desontologização e uma conseqüente semantização da noção de propriedade. Propriedades devem ser consideradas aqui muito mais como critérios para atribuição de nomes do que como atributos de substâncias. Uma das críticas que se pode (e se costuma) fazer à teoria dos nomes de Mill baseia-se na afirmação de que sua semântica promove, para ser coerente consigo mesma, a necessidade de um certo comprometimento ontológico. Deveríamos nos comprometer com um quase leibnizianismo ontológico e acreditar que os objetos possuem uma certa essência determinada pela posse de um conjunto de atributos. Existem, de fato, algumas passagens na obra de Mill que fornecem, aparentemente, subsídios para esta leitura; por exemplo, quando Mill afirma, contra Hobbes e sua estirpe de nominalistas, que os nomes não se referem a idéias, mas às coisas mesmas, e que, portanto, os predicados conotados pelos nomes conotativos são propriedades das coisas mesmas. ${ }^{23}$ Porém, ao meu ver, esta leitura não é correta. Quando se encaram

23 MILL, J. S. : op. cit. 1, II, p.1 
as coisas dessa maneira não se percebe o que talvez tenha sido uma grande contribuição de Stuart Mill para a história da filosofia, a saber, de ter lançado as bases do que se acostumou chamar de giro semântico na medida em que concebe o processo de significação como algo complexo, delegando aos nomes e às proposições (no caso, instâncias lógico-lingüístico-semânticas) o papel de carregar essa carga significativa. Propriedades são critérios mínimos estabelecidos pelos nomes para que os objetos possam por eles ser nomeados. Quando digo "critérios mínimos" quero dizer que um nome conotativo não deve e não precisa esgotar todas as determinações ontológicas que constituem as essências de supostas substâncias; deve, antes, estabelecer alguma ou algumas características dos objetos suficientes para que o nome lhes seja atribuído.

\section{VIII}

Dentro da perspectiva sistemática, uma observação deve ser feita: se, na definição milliana de nome próprio, pusermos ênfase no caráter invidualizador desses nomes, talvez não esteja fora de propósito considerar contraditórios os tais nomes próprios gerais, se não de forma absoluta, ao menos internamente ao sistema de Mill. Se o objetivo do nome próprio é, em última análise, tornar algo distinto e assinalar sua individualidade, não se poderia atribuir esses nomes senão a objetos singulares - mesmo que coletivos, mas, acima de tudo, singulares. Os nomes próprios gerais seriam, assim, incompatíveis com a organicidade interna do sistema milliano. Um nome próprio que, como vimos, não possui significação, tem a função exclusiva de referir-se a objetos individuais.

Um nome próprio nada mais é do que uma marca insignificante ${ }^{24}$ que unimos em nosso espírito com a idéia do objeto, para que sempre que a marca se ponha diante de nossos olhos ou nos venha ao espírito possamos pensar nesse objeto individual. (o grifo é meu) ${ }^{25}$

Uma outra questão deve ser considerada: vimos, há pouco, que Mill oferece uma crítica àquilo que poderíamos chamar de nominalismo ingênuo, na medida em que não aceita de forma absoluta a tese de que nomes se referem a idéias de coisas ao invés de se referirem às coisas mesmas. Os nomes conotativos, que são a maioria e aqueles que têm

24 Isto é, sem significação.

25 MILL, J..S. Op. cit., II, p. 5. 
propriamente significado, se referem às coisas mesmas; somente os nomes próprios referem-se a idéias. ${ }^{26}$ Ora, se for possível a ocorrência de nomes próprios gerais, teremos que aceitar a tese estranha de que um mesmo nome possa se referir num mesmo sentido a mais de uma idéia. O nome "catapufe" sugerido há pouco manteria uma relação semântica - e a mesma relação! - com as idéias de cada um dos três indivíduos supostamente por ele denotados. Parece-me, neste caso, que se são três os indivíduos a serem denotados (e, conseqüentemente, três idéias a serem associadas ao nome), deva haver ou três nomes distintos associados a cada uma das idéias, ou três sentidos distintos associados ao nome.

A partir dos argumentos propostos, defendo que a tese milliana de que todos os nomes gerais são conotativos deve ser mantida, seja quando se analisa a filosofia de Mill propriamente dita, seja quando se busca aplicar os resultados de Mill à linguagem tal como efetivamente é utilizada em situações reais. Tanto do ponto de vista pragmático, quanto sistemático, a tese da necessária conotabilidade dos nomes gerais se mostra, a meu ver, pertinente e correta. Em poucas palavras, podemos resumir a questão da seguinte forma: generalidade semântica é um conceito que está diretamente relacionado ao conceito de conotação; somente pode ser geral um nome que conota. Nomes não-conotativos não podem almejar nenhuma generalidade.

Marília, setembro de 2004

PRADO, L. L. General proper names in the context of Stuart Mill's semantic. Trans/Form/Ação, (São Paulo), v.28(1), 2005, p.67-83.

- ABSTRACT: This paper presents arguments in defense of the hypothesis that general proprer names are impossible in the context of Stuart Mill's philosophy of language. My thesis is contrary to John Skorupski's position to this subject. I offer two arguments related, respectively, to two different perspectives: the pragmatic and the systematic. In the first one I analyze the problem of general proper names in the context of natural language. In the second one I discuss this problem in the inner context of Mill's System of logic.

- KEYWORDS: name, meaning, connotation, denotation, semantic.

26 Isto porque as propriedades conotadas pelo nome conotativo são propriedades das coisas e não das idéias das coisas. 